\title{
Nanocomposite selenium - containing substances and effect on ring rot of potatoes
}

\author{
Nozhkina O.A. ${ }^{1 *}$, Perfileva A.I. ${ }^{1}$, Graskova I.A. ${ }^{1,3}$, Sukhov B.G. ${ }^{2,3}$ \\ ${ }^{1}$ Siberian Institute of Plant Physiology and Biochemistry, SB RAS, Irkutsk, Russia \\ ${ }^{2}$ A.E. Favorsky Irkutsk Institute of Chemistry, SB RAS, Irkutsk, Russia \\ ${ }^{3}$ Irkutsk Scientific Center, Irkutsk, Russia \\ *e-mail: smallolga@mail.ru
}

Potato plants are susceptible to ring rot disease caused by the bacterium Clavibacter michiganensis ssp. sepedonicus ( $\mathrm{Cms}$ ). In the fight with disease use of aggressive and environmentally safe reagents. The study uses nanocomposite substances containing selenium (NC Se) in the natural matrix membranes of starch, karaginan and arabinogalactan as environmentally safe means of combating the disease. Synthesis of NC Se oxidation was carried out organil desalineamiento of sodium by hydrogen peroxide with the subsequent formation of selenium nanoparticles and their simultaneous stabilization of natural matrix. All NC Se were synthesized in Irkutsk Institute of Chemistry SB RAS. They are easily soluble in water and convenient to use their aqueous solutions. The synthesized NC is a well water-soluble powder, possessing bacteriostatic properties. Selenium concentration, which was $0.000625 \%$, was used for the experiments. Potato plants grown in vitro of the susceptible variety Lukyanovskii were incubated with the bacterium Cms of the strain Ac-1405 for 18-21 days and monitored the change in biometric parameters of plant growth and development. Studies have shown that NC Se does not have a negative effect on plants, but when infected, its effect decreases. In the study of peroxidase activity, it was found NC Se/AG reduces the index, which indicates the presence of stress in plants. In studies on the Cms during incubation with solutions of $\mathrm{NC}$ expressed negative effect of $\mathrm{NC}$ was not revealed. But in vain consideration of the growth rate of bacterial biomass was found $\mathrm{NC} \mathrm{Se/AG} \mathrm{inhibits} \mathrm{bacterial} \mathrm{growth.} \mathrm{Se}$ accumulation in plant tissues was investigated by X-ray energy dispersive microanalysis. The data obtained did not reveal Se accumulation. The results indicate the prospects of the study of NC Se as an environmentally safe means for the improvement of potatoes with bacteriostatic and bactericidal properties.

Acknowledgements: This study was supported by the Russian Science Foundation. The work is supported by the grant of the President of the Russian Federation No. MK1220.2019.11. 